\title{
PENGARUH BRAND EXPERIENCE DAN BRAND IMAGE TERHADAP WILLINGNESS TO PAY A PRICE PREMIUM DENGAN BRAND LOVE SEBAGAI VARIABEL INTERVENING (Studi Pada Pemilik Mobil Merek Honda HRV di Samarinda)
}

\author{
Mega Aulianda \\ Magister Manajemen Universitas Mulawarman \\ megaaulianda22@gmail.com
}

Syarifah Hudayah

FEB Universitas Mulawarman

syarifah.hudaya@feb.unmul.ac.id

\author{
Rahmawati \\ FEB Universitas Mulawarman \\ rahmawati@feb.unmul.ac.id
}

\section{ABSTRACT}

This study aims to determine the effect of brand experience and brand image on the willingness to pay a premium price for Honda HRV products in Samarinda mediated by brand love variable. Data collection in this study was carried out by using an instrument in the form of a set of questionnaires distributed to 95 owners of Honda HRV cars within Samarinda area. Data from the questionnaires were subsequently analyzed using SEM-PLS analysis techniques with the help of the smartpls version

3.9 program.

Based on the results of the analysis in this study, it is obtained that directly, brand experience, brand image and brand love have positive and significant effects on the willingness to pay a premium price. The results of the analysis also showed that brand experience and brand image have positive and significant effects on brand love; and brand love proved to be able to mediate the indirect effect of brand experience and brand image on the willingness to pay a premium price for Honda HRV product consumers. The findings of this study indicate that the better the brand image of Honda HRV and the higher brand experience of Honda HRV consumers, the higher the brand love of consumers which will further increase the desire of consumers to buy HRV products even at high prices.

Theoretically, the findings of this study are in accordance with some previous researches and existing theories. Practically the findings of this research are expected to be a scientific reference for business people in automotive sector, especially in Samarinda to build brands effectively and efficiently.

Keywords: Brand Experience, Brand Image, Willingness To Pay a Price Premium, Brand Love

\section{PENDAHULUAN}

Dalam industri otomotif persaingan antar merek tentu tidak dapat dihindari. Produsen otomotif terus berusaha untuk memenangkan persaingan dengan menghasilkan produk-produk yang memiliki berbagai keunggulan dari produk pesaingnya. Mulai dari perencanaan, produksi, pemasaran, pendistribusian sampai dengan pelayanan purna jual semua merek otomotif berlomba untuk memberikan yang terbaik kepada konsumen.

Indonesia merupakan pangsa pasar yang potensial bagi merek-merek otomotif. Mulai dari otomotif kelas low price sampai dengan kelas premium semua ada di Indonesia dengan berbagai merek yang berasal dari produsen luar negeri.

Di Indonesia segmen otomotif yang cukup besar adalah adalah mobil dengan kapasitas mesin kecil yaitu $1000 \mathrm{cc}$ sampai dengan $1500 \mathrm{cc}$. Hampir semua merek mobil yang beredar di Indonesia memiliki produk mobil-mobil pada segmen ini.

Memiliki harga yang paling tinggi dan kapasitas penumpang paling sedikit diantara produk sejenis dari berbagai merek merupakan tantangan bagi produsen Honda untuk bersaing merebut hati konsumen. Fenomena ini menarik 
penulis untuk melakukan penelitian secara mendalam dan ilmiah terhadap faktor-faktor yang mempengaruhi konsumen untuk membeli mobil merek Honda HRV.

Penulis telah melakukan studi awal terhadap beberapa konsumen mobil merek Honda HRV dengan cara melakuan meminta pendapat mereka tetang mobil Honda HRV dan alasan mengapa mereka membelinya. Beragam pendapat dan alasan yang merek ungkapkan yang membuat penulis tertarik untuk melakukan penelitian secara mendalam dan ilmiah terhadap fenomena kesediaan konsumen membayar harga yang lebih mahal atas mobil Honda HRV.

\section{Kajian Pustaka}

\section{Brand}

Brand adalah istilah yang terkait erat dengan citra dan reputasi produk atau tempat dalam arti tentang reputasi yang diamati, reputasi yang dihargai, dan pengelolaan reputasi (Anholt, 2010:20)

Menurut Chiaravalle dan Shanck, (2007:22) Sebuah janji tentang siapa Anda dan manfaat apa yang Anda berikan yang diperkuat setiap kali orang berhubungan dengan Anda atau bisnis Anda.

Kotler dan Pfoertsch, (2006:5) memberikan pendapat tentang Brand adalah:

a. Merek adalah janji.

b. Merek sepenuhnya adalah persepsi (segala sesuatu yang kita lihat, dengar, baca, ketahui, masukan pikiran dan lain lain) tentang suatu produk, jasa atau bisnis.

c. Merek memiliki posisi istimewa di benak customer berdasarkan pengalaman masa lalu, pergaulan dan ekspektasi masa depan.

d. Merek adalah jalan pintas atribut, manfaat, keyakinanan dan nilai yang membedakan, mengurangi kompleksitas, dan menyederhanakan proses pengambilan keputusan.

Brand menurut Kartajaya,(2006:184) yaitu indikator yang menggambarkan seberapa kokoh dan solidnya value yang Anda tawarkan ke pelanggan.

Sementara Aaker, (1991:7) menyatakan " $A$ Brand is a distinguishing name and/or symbol (such as a logo, trade-mark, or package design) intended to identity thr goods or services of either one seller or a group of sellers, and to differentiate those goods osr services from those of competitors".
Menurut Betay, (2008) perbedaan produk dan brand adalah:

a. Konsumen membeli produk untuk apa fungsinya dan mereka memilih merek untuk alasan yang berararti.

b. Produk terdapat di atalese atau gerai penjualan, sementara merek berada dalam benak atau pikiran konsumen.

c. Suatu produk dapat dengan cepat usang, tetapi sebuah merek adalah abadi.

d. Suatu produk dapat disalin atau ditiru pesaing, sedangkan merek memiliki suatu keunikan yang sulit untuk ditiru.

\section{Brand Experience}

Brand experience dimulai pada saat konsumen mencari produk, membeli, menerima pelayanan dan mengkonsumsi produk. Pengalaman produk terjadi ketika konsumen berinteraksi dengan produk, misalnya ketika konsumen mencari produk, memeriksa dan mengevaluasinya (Brakus, Schmit dan Zarantonello, 2009)..

Pengalaman berbelanja dan pelayanan terjadi ketika konsumen berinteraksi dengan lingkungan fisik toko, personelnya, dan kebijakan serta praktiknya (Brakus et. al., 2009)

Pengalaman konsumsi bersifat multidimensi dan mencakup dimensi hedonis seperti perasaan, fantasi, dan kesenangan (Brakus et. al., 2009).

Menurut Dwivedy, Nayeem dan Murshed, (2018) Sensasi, perasaan, kognisi, dan respon perilaku yang ditimbulkan oleh rangsangan terkait merek yang merupakan bagian dari desain dan identitas merek, pengemasan, komunikasi, dan lingkungan.

Menurut Brakus et. al., (2009) terdapat 4 dimensi brand experience:

a. Sensorik, menciptakan pengalaman melalui penglihatan, suara, sentuhan, bau dan rasa.

b. Afeksi, pendekatan perasaan dengan mempengaruhi suasana hati, perasaan dan emosi

c. Perilaku, menciptakan pengalaman secara fisik, pola perilaku, gaya hidup.

d. Intelektual, menciptakan pengalaman yang mendorong konsumen terlibat dalam pemikiran seksama mengenai keberadaan suatu merek.

\section{Brand Image}


Menurut Lee, James and Kim, (2014) Brand image adalah persepsi pelanggan tentang merek yang dihasilkan oleh interaksi proses kognitif, afektif, dan evaluatif dalam benak pelanggan.

Menurut Chiaravalle dan Shanck, (2007:22) Brand image adalah Suatu kepercayaan tentang merek yang ada dalam benak pelanggan sebagai akibat dari asosiasi merek dan produk.

Lee et al., (2011) Brand image dapat digambarkan sebagai citra mental unik keseluruhan yang dimiliki konsumen untuk suatu merek.

Menurut Setiadi dan Ngatno, (2015) Brand image merupakan keseluruhan persepsi terhadap suatu merek yang dibentuk dengan memproses informasi dari berbagai sumber setiap waktu. Citra merek dibangun berdasarkan kesan, pemikiran ataupun pengalaman yang dialami oleh seseorang terhadap suatu merek yang pada akhirnya akan membentuk sikap terhadap merek yang bersangkutan.

Menurut Halim, Swasto dan Hamid, (2014) Brand image lebih kepada apa yang ada di dalam benak konsumen terhadap suatu produk. Konsumen memiliki bayangan dan persepsi sendiri terhadap suatu merek yang merupakan hasil dari asosiasi merek yang dibangun oleh perusahaan.

Perusahaan bersaing untuk memberikan ide bagus tentang produk dan pelayanan mereka untuk membangun citra positif tentang merek mereka di benak pelanggan. Jadi, persepsi yang baik tentang kualitas produk dan pelayanan akan mendorong pelanggan untuk membentuk citra merek yang positif (Sallam, 2014).

\section{Brand Love}

Menurut Meisenzahl, (2017) Cinta adalah perasaan yang penuh gairah yag didalamnya terdapat daya tarik fisik dan emosi manusia terhadap manusia lain.

Menurut Carrol dan Ahuvia, (2006) Cinta merek didefinisikan sebagai tingkat keterikatan emosional yang kuat yang dimiliki oleh konsumen yang puas terhadap merek tertentu.

Sementara Bambang,

mendefinisikan cinta merek sebagai cinta yang sangat terasa bagi sebuah merek. Cinta merek, berarti emosi konsumen yang kuat terhadap merek tertentu. Cinta merek terdiri dari dua aspek utama yaitu rasa dan gairah.
Menurut Ismail dan Gabriella dalam Pangestu, (2018) menyatakan bahwa kecintaan konsumen memiliki karakteristik sebagai berikut :
a. Ketertarikan terhadap merek
b. Keterikatan merek
c. Penilaian positif terhadap merek
d. Emosi yang positif dalam merespon merek
e. Deklarasi kecintaan terhadap merek

\section{Willingness to pay a price premium}

Limpele, (2013) menyatakan bahwa keputusan penetapan harga adalah bagian dari konsep merek, ditentukan oleh strategi perusahaan, dan disesuaikan dengan tingkat produk / merek.

Bondesson, (2012). Suatu merek memiliki harga premium ketika pelanggan bersedia membayar untuk produk atau pelayanan dari suatu merek lebih tinggi daripada jumlah yang mereka bayarkan untuk penawaran serupa dari merek lain.

Willingness to pay a price premium menunjukkan keinginan konsumen untuk membayar harga yanglebih tinggi bagi produk yang dijual perusahaan. Penetapan harga premium ialah penetapan harga yang lebih tinggi oleh perusahaan karena keunggulan yang dirasakan konsumen dari suatu produk (Gregg \& Walczak, 2015)

Suatu merek memperoleh harga premium ketika jumlah yang rela dibayarkan pelanggan untuk produk dari merek tersebut lebih tinggi daripada jumlah yang mereka bayarkan untuk produk serupa dari merek lain yang relevan (Anselmsson et. al., 2014).

Menurut Lumba, (2019) Price premium didefinisikan sebagai keinginan konsumen untuk membayar lebih tinggi untuk sebuah merek tertentu dibandingkan dengan merek lainnya. Price premium diukur dari selisih harga yang lebih tinggi dari sebuah merek dibandingkan merek lain.

\section{Kerangka Konsep}

Berdasarkan teori dan latar belakang permasalahan, disajikan kerangka konseptual dari penelitian sebagai berikut: 


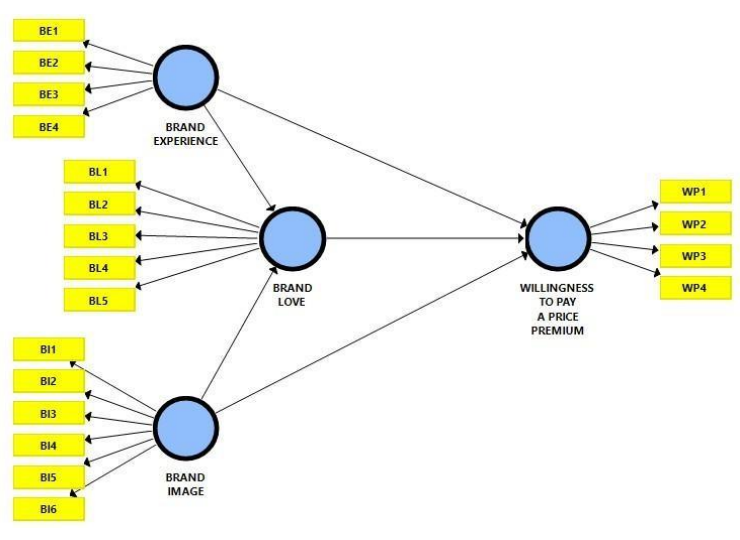

Gambar 2.1 Kerangka Konsep

\section{Hipotesis}

Berdasarkan kerangka konsep penelitian tersebut dapat di hipotesiskan sebagai berikut:

$\mathrm{H} 1$ : Brand Experience berpengaruh terhadap Brand Love.

$\mathrm{H} 2$ : Brand Image berpengaruh terhadap Brand Love.

H3: Brand Experience berpengaruh terhadap Willingness to pay a price premium.

H4: Brand Image berpengaruh terhadap Willingness to pay a price premium.

H5: Brand Love berpengaruh terhadap Willingness to pay a price premium.

H6: Brand Love memediasi pengaruh Brand Experience terhadap Willingness to pay a price premium.

H7: Brand Love memediasi pengaruh Brand Image terhadap Willingness to pay a price premium

\section{METODE PENELITIAN}

Dalam penelitian ini, analisis pengaruh brand experience dan brand image terhadap willingness to pay premium dengan dimediasi oleh variabel brand love akan dianalisis dengan menggunakan teknik analisis Partial Least Square (PLS) dengan bantuan program Smartpls dengan sumber data dari 95 responden.

Dalam penelitian ini, variabel brand experience diukur dengan 4 indikator, variabel brand image diukur dengan 6 indikator, variabel brand love diukur dengan 5 indikator dan variabel willingness to pay premium diukur dengan 4 indikator sehingga spesifikasi model PLS yang akan diestimasi dalam penelitian ini adalah sebagai berikut :

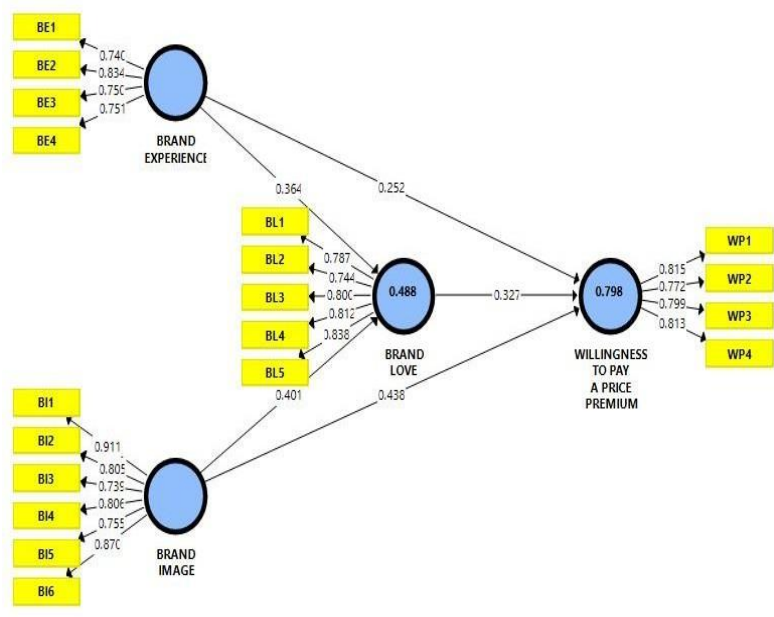

Gambar 5.1. Hasil Estimasi Full Model PLS Sumber: data primer diolah

Nilai AVE masing-masing konstruk selengkapnya dapat dilihat pada tabel berikut:

Tabel 5.1

Nilai Loading factor dan Nilai AVE

\begin{tabular}{|c|c|c|c|c|}
\hline Variabel & Indikator & $\begin{array}{l}\text { Loading } \\
\text { Factor }\end{array}$ & AVE & $\begin{array}{c}\text { Validi } \\
\text { tas }\end{array}$ \\
\hline \multirow{4}{*}{$\begin{array}{c}\text { Brand } \\
\text { Experience }\end{array}$} & BE1 & 0,740 & \multirow{4}{*}{0,592} & valid \\
\hline & BE2 & 0,834 & & valid \\
\hline & BE3 & 0,750 & & valid \\
\hline & BE4 & 0,751 & & valid \\
\hline \multirow{6}{*}{$\begin{array}{l}\text { Brand } \\
\text { image }\end{array}$} & BI1 & 0,911 & \multirow{6}{*}{0,667} & valid \\
\hline & $\mathrm{BI} 2$ & 0,805 & & valid \\
\hline & $\mathrm{BI} 3$ & 0,739 & & valid \\
\hline & BI4 & 0,806 & & valid \\
\hline & BI5 & 0,755 & & valid \\
\hline & BI6 & 0,870 & & valid \\
\hline \multirow{5}{*}{ Brand love } & BL1 & 0,787 & \multirow{5}{*}{0,635} & valid \\
\hline & BL2 & 0,744 & & valid \\
\hline & BL3 & 0,800 & & valid \\
\hline & BL4 & 0,812 & & valid \\
\hline & BL5 & 0,838 & & valid \\
\hline \multirow{4}{*}{$\begin{array}{c}\text { Willingness } \\
\text { to pay a } \\
\text { price } \\
\text { premium }\end{array}$} & WTP1 & 0,815 & \multirow{4}{*}{0,64} & valid \\
\hline & WTP2 & 0,772 & & valid \\
\hline & WTP3 & 0,799 & & valid \\
\hline & WTP4 & 0,813 & & valid \\
\hline
\end{tabular}

Sumber: data primer diolah 
Berdasarkan hasil analisis PLS pada tabel di atas, nilai loading afctor seluruh indikator > 0,7 dan AVE seluruh variabel telah melebihi 0,5 yang menunjukkan bahwa seluruh indikator pada masing-masing konstruk telah memenuhi kriteria validitas konvergen yang disyaratkan memiliki nilai akar kuadrat AVE di atas nilai korelasi dengan konstruk laten lainnya sehingga dapat disimpulkan bahwa model telah memenuhi validitas deskriminan.

Tabel 5.2

Hasil Uji Validitas Dekriminan

\begin{tabular}{|c|c|c|c|c|}
\hline & BE & BI & BL & WTP \\
BE & 0,77 & & & \\
\cline { 2 - 5 } BI & 0,668 & 0,817 & & \\
\cline { 2 - 5 } BL & 0,632 & 0,644 & 0,797 & \\
\cline { 2 - 5 } WTP & 0,751 & 0,817 & 0,768 & 0,800 \\
\hline
\end{tabular}

Sumber: data primer diolah

Tabel 5.3

Hasil Uji Reliabilitas Komposit

\begin{tabular}{|c|c|c|}
\hline & $\begin{array}{c}\text { Cronbach's } \\
\text { Alpha }\end{array}$ & $\begin{array}{c}\text { Composite } \\
\text { Reliability }\end{array}$ \\
\hline BE & 0,770 & 0,853 \\
\hline BI & 0,899 & 0,923 \\
\hline BL & 0,856 & 0,897 \\
\hline WTP & 0,813 & 0,876 \\
\hline
\end{tabular}

Sumber: data primer diolah

Hasil uji reliabilitas pada tabel di atas menunjukkan bahwa seluruh konstruk telah memiliki nilai composite reliability $>0,7$ dan cronbachs alpha $>0,7$ yang menunjukkan bahwa seluruh konstruk telah memenuhi reliabilitas yang disyaratkan.

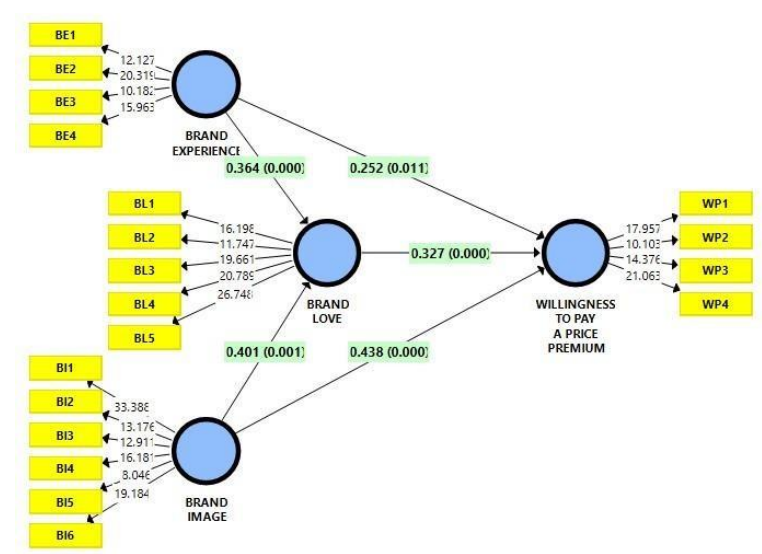

Gambar 5.3. Full model PLS Boootstrapping
Berdasarkan hasil estimasi model PLS dengan teknik bootstrapping di atas, seluruh jalur memiliki nilai $\mathrm{p}$ value $<0,05$. Hasil uji signifikansi pengaruh langsung ini selengkapnya dapat dilihat pada tabel berikut:

Tabel 5.5

Hasil Pengujian Pengaruh Langsung

\begin{tabular}{|l|c|c|c|c|c|}
\hline & $\begin{array}{c}\text { Original } \\
\text { Sample } \\
(O)\end{array}$ & $\begin{array}{c}\text { Sample } \\
\text { Mean } \\
(M)\end{array}$ & $\begin{array}{c}\text { Standard } \\
\text { Deviation } \\
(\text { STDEV })\end{array}$ & $\begin{array}{c}\text { T Statistics } \\
\mid \text { O/STDEV } \mid\end{array}$ & $\begin{array}{c}P \\
\text { Values }\end{array}$ \\
\hline $\begin{array}{l}\text { BE -> } \\
\text { BL }\end{array}$ & 0.364 & 0.373 & 0.077 & 4.740 & 0.000 \\
\hline $\begin{array}{l}\text { BE -> } \\
\text { WTP }\end{array}$ & 0.252 & 0.256 & 0.099 & 2.545 & 0.011 \\
\hline $\begin{array}{l}\text { BI -> } \\
\text { BL }\end{array}$ & 0.401 & 0.391 & 0.116 & 3.444 & 0.001 \\
\hline \begin{tabular}{l|c|c|c|c|c|}
\hline BI-> \\
WTP
\end{tabular} & 0.438 & 0.433 & 0.101 & 4.325 & 0.000 \\
\hline $\begin{array}{l}\text { BL-> } \\
\text { WTP }\end{array}$ & 0.327 & 0.328 & 0.076 & 4.293 & 0.000 \\
\hline
\end{tabular}

Sumber: data primer diolah

Tabel 5.6

Hasil Pengujian Pengaruh Tidak Langung

\begin{tabular}{|l|c|c|c|c|c|}
\hline & $\begin{array}{c}\text { Original } \\
\text { Sample } \\
(O)\end{array}$ & $\begin{array}{c}\text { Sample } \\
\text { Mean } \\
(M)\end{array}$ & $\begin{array}{c}\text { Standard } \\
\text { Deviation } \\
(\text { STDEV })\end{array}$ & $\begin{array}{c}\text { T Statistics } \\
(\mid \text { OSTDEV })\end{array}$ & $\begin{array}{c}P \\
\text { Values }\end{array}$ \\
\hline $\begin{array}{l}\text { BE -> } \\
\text { BL -> } \\
\text { WTP }\end{array}$ & 0.119 & 0.122 & 0.036 & 3.345 & 0.001 \\
\hline $\begin{array}{l}\text { BI -> } \\
\text { BL-> } \\
\text { WTP }\end{array}$ & 0.131 & 0.132 & 0.058 & 2.270 & 0.024 \\
\hline
\end{tabular}


Tabel 5.7

Ringkasan Hasil Pengujian Hipotesis

\begin{tabular}{|c|c|c|c|}
\hline No & Hipotesis & $\begin{array}{l}P \text { Value / } T \\
\text { Value }\end{array}$ & Keputusan \\
\hline 1 & $\begin{array}{l}\text { Brand Experience berpengaruh } \\
\text { terhadap Brand Love }\end{array}$ & $\begin{array}{l}0,000 / \\
4,740\end{array}$ & diterima \\
\hline 2 & $\begin{array}{l}\text { Brand Image berpengaruh } \\
\text { terhadap Brand Love }\end{array}$ & $\begin{array}{l}0,001 / \\
3,444\end{array}$ & diterima \\
\hline 3 & $\begin{array}{l}\text { Brand Experience berpengaruh } \\
\text { terhadap Willingness to pay a } \\
\text { price premium. }\end{array}$ & $\begin{array}{l}0,011 / \\
2,545\end{array}$ & diterima \\
\hline 4 & $\begin{array}{l}\text { Brand Image berpengaruh } \\
\text { terhadap Willingness to pay a } \\
\text { price premium. }\end{array}$ & $\begin{array}{l}0,000 / \\
4,325\end{array}$ & diterima \\
\hline 5 & $\begin{array}{l}\text { Brand Love berpengaruh } \\
\text { terhadap Willingness to pay a } \\
\text { price premium. }\end{array}$ & $\begin{array}{l}0,000 / \\
4,293\end{array}$ & diterima \\
\hline 6 & $\begin{array}{l}\text { Brand Love memediasi } \\
\text { pengaruh Brand Experience } \\
\text { terhadap Willingness to pay a } \\
\text { price premium. }\end{array}$ & $\begin{array}{l}0,001 / \\
3,345\end{array}$ & diterima \\
\hline 7 & $\begin{array}{l}\text { Brand Love memediasi } \\
\text { pengaruh Brand Image } \\
\text { terhadap Willingness to pay a } \\
\text { price premium. }\end{array}$ & $\begin{array}{c}0,024 / \\
2,270\end{array}$ & diterima \\
\hline
\end{tabular}

Sumber: data primer diolah

\section{Pembahasan \\ Pengaruh Brand experience terhadap Brand Love}

Hasil analisis dalam penelitian ini menunjukkan bahwa Brand experience berpengaruh positif dan signifikan terhadap brand love konsumen produk Honda HRV. Semakin tinggi brand experience konsumen Honda HRV maka semakin tinggi brand love konsumen. Selanjutnya nilai koefisien jalur sebesar 0,364 menunjukkan bahwa besar kontribusi yang diberikan brand experience terhadap brand love konsumen adalah sebesar $36,4 \%$.

Hasil penelitian ini sejalan dengan hasil ppenelitian Bambang et.al., (2017) yang menyatakan bahwa Brand Experience PT. Oro Kopi Gayo berpengaruh terhadap Brand Love. Hal ini mengindikasikan bahwa dengan semakin baik Brand Experience yang dimiliki oleh konsumen akan meningkatkan Brand Love, karena konsumen merasakan sesuatu yang berbeda ketika mencoba merek yang berbeda dari merekproduk yang sama.

Hasil penelitian ini juga sejalan dengan hasil penelitian Madeline dan Sihombing, (2019) Brand Experience yang terdiri dari Sensory Experience, Intellectual Experience, dan Behavioral Experience berpengaruh positif terhadap Brand Love. Terdapat efek positif dari pengalaman merek (pengalaman sensorik, pengalaman intelektual, dan pengalaman perilaku) pada Brand Love.

\section{Pengaruh Brand image terhadap Brand Love}

Hasil analisis dalam penelitian ini menunjukkan bahwa Brand image berpengaruh positif dan signifikan terhadap brand love konsumen produk Honda HRV. Semakin tinggi brand image produk Honda HRV maka semakin tinggi brand love produk. Selanjutnya nilai koefisien jalur sebesar 0,401 menunjukkan bahwa besar kontribusi yang diberikan brand image terhadap brand love konsumen adalah sebesar $40,1 \%$.

Hasil penelitian ini sejalan dengan hasil penelitian Bambang et.al., (2017) bahwa Brand Image PT. Oro Kopi Gayo mempunyai pengaruh terhadap Brand Love PT. Oro Kopi Gayo. Hal ini mengindikasikan bahwa dengan semakin baiknya Brand Image PT. Oro Kopi Gayo akan memberikan pengaruh positif dan nyata terhadap peningkatan Brand Love PT. Oro Kopi Gayo terutama dalam dalam melakukan pembelian ulang.

Hasil penelitian ini sejalan dengan isi artikel Ismail dan Spineli. (2012) yang mengungkapkan bahwa hanya citra merek yang dianggap sebagai penentu Brand Love yang mempengaruhi WTP bersama dengan kepribadian merek.

\section{Pengaruh Brand experience terhadap Willingness to Pay a price premium}

Hasil analisis dalam penelitian ini menunjukkan bahwa Brand experience berpengaruh positif dan signifikan terhadap willingness to pay a price premium konsumen produk Honda HRV. Semakin tinggi brand experience konsumen maka semakin tinggi minat konsumen untuk membeli Honda HRV dengan harga tinggi. Selanjutnya nilai koefisien jalur sebesar 0,252 menunjukkan bahwa besar kontribusi yang diberikan brand experience 
terhadap willingness to pay a price premium konsumen adalah sebesar $25,2 \%$.

Hasil penelitian ini mendukung hasil penelitian Dwivedi et. al., (2018) yang menyatakan bahwa brand experience berpengaruh positif terhadap willingness to pay a price premium.

Pengalaman merek secara positif dan signifikan berdampak pada kesediaan konsumen untuk membayar harga premium. Ketika konsumen secara pribadi mendapatkan pengalaman dengan suatu merek, mereka kemungkinan akan membayar harga premium untuk merek tersebut di masa depan. Argumen ini menunjukkan bahwa pengalaman merek yang positif akan meningkatkan kemungkinan konsumen untuk membayar harga yang lebih tinggi.

Pengaruh Brand image terhadap Willingness to pay a price premium

Hasil analisis dalam penelitian ini menunjukkan bahwa Brand image berpengaruh positif dan signifikan terhadap willingness to pay a price premium konsumen produk Honda HRV. Semakin tinggi brand image produk Honda HRV maka semakin tinggi minat konsumen untuk membeli Honda HRV dengan harga tinggi. Selanjutnya nilai koefisien jalur sebesar 0,438 menunjukkan bahwa besar kontribusi yang diberikan brand image terhadap willingness to pay a price premium konsumen adalah sebesar $43,8 \%$.

Hasil penelitian ini sejalan dengan hasil penelitian Anselmsson, Bondesson dan Johanson, (2014) yang menyatakan bahwa semua faktor dari Brand Image yaitu awareness, quality, social image, CSR, home country origindan uniqueness memiliki pengaruh positif terhadap Willingness to pay a price premium.

Dalam penelitian yang dilakukan oleh Munir et. al., (2017) dihasilkan bahwa there is positive relationship between Dependent Variable Price Premium and all independent variables that are awareness, quality, corporate social responsibility, country of origin, social image, and uniqueness because of the positive values for correlation. Price Premium has a high relationship with social image.

Pengaruh Brand love terhadap Willingness to pay a price premium

Hasil analisis dalam penelitian ini menunjukkan bahwa Brand love berpengaruh positif dan signifikan terhadap willingness to pay a price premium konsumen produk Honda HRV. Semakin tinggi brand love konsumen terhadap produk Honda HRV maka semakin tinggi minat konsumen untuk membeli Honda HRV dengan harga tinggi. Selanjutnya nilai koefisien jalur sebesar 0,327 menunjukkan bahwa besar kontribusi yang diberikan brand love terhadap willingness to pay a price premium konsumen adalah sebesar $32,7 \%$.

Hasil penelitian ini sejalan dengan hasil penelitian yang dilakukan oleh Pangestu, (2018) yang meenyatakan bahwa Brand Love memiliki pengaruh yang signifikan terhadap Willingness to pay a Premium Price. Dari rata-rata pernyataan variable Brand Love dapat disimpulkan bahwa poin "saya memimpikan Rolex ini sudah lama sekali" memberikan pernyataan paling valid dalam variable Brand Love.

Hasil penelitian Lumba (2019) juga menunjukkan bahwa bahwa ketika tingkat kecintaan terhadap merek semakin kuat menyebabkan willingness to pay price premium juga semakin kuat dan ketika tingkat kecintaan terhadap merek semakin lemah juga menyebabkan willingness to pay price premium semakin lemah.

\section{Pengaruh Brand Experience terhadap Willingness to pay price peremium melalui Brand Love}

Hasil analisis dalam penelitian ini menunjukkan bahwa brand experience berpengaruh positif dan signifikan terhadap willingness to pay price premium dengan dimediasi oleh brand love konsumen. Hal ini menunjukkan bahwa semakin tinggi brand experience konsumen maka semakin tinggi brand love konsumen yang selanjutnya akan meningkatkan willingness to pay price premium konsumen.

Peran brand love dalam memediasi pengaruh brand experience terhadap willingness to pay a price premium ini bersifat partial mediation, hal ini karena tanpa dimediasi oleh brand love, brand experience akan berpengaruh secara tidak langsungu terhadap willingness to pay price premium.

\section{Pengaruh Brand Image terhadap Willingness to pay price peremium melalui Brand Love \\ Hasil analisis dalam penelitian} ini menunjukkan bahwa brand image 
berpengaruh positif dan signifikan terhadap willingness to pay price premium dengan dimediasi oleh brand love konsumen. Hal ini menunjukkan bahwa semakin tinggi brand image produk maka semakin tinggi brand love konsumen yang selanjutnya akan meningkatkan willingness to pay price premium konsumen.

Peran brand love dalam memediasi pengaruh brand image terhadap willingness to pay a price premium ini bersifat partial mediation, hal ini karena dengan dimediasi oleh brand love, brand image akan berpengaruh secara tidak langsung terhadap willingness to pay price premium.

\section{KESIMPULAN}

a. Brand experience dan brand image masing- masing berpengaruh positif dan signifikan terhadap brand love konsumen produk Honda HRV. Semakin tinggi brand experience dan brand image maka semakin tinggi brand love konsumen.

b. Brand experience dan brand image masing- masing berpengaruh positif dan signifikan terhadap willingness to pay a price premium konsumen produk Honda HRV. Semakin tinggi brand experience dan brand image maka semakin tinggi minat konsumen untuk membeli Honda HRV dengan harga yang lebih tinggi dari produk kompetitor.

c. Brand love berpengaruh positif dan signifikan terhadap willingness to pay a price premium konsumen produk Honda HRV. Semakin tinggi brand love konsumen terhadap produk Honda HRV maka semakin tinggi minat konsumen untuk membeli Honda HRV dengan harga tinggi.

d. Brand experience berpengaruh positif dan signifikan terhadap williness to pay price premium dengan dimediasi oleh brand love konsumen. Hal ini menunjukkan bahwa semakin tinggi brand experience konsumen maka semakin tinggi barnd love konsumen yang selanjutnya akan meningkatkan willingness to pay price premium konsumen.

e. Brand image berpengaruh positif dan signifikan terhadap williness to pay price premium dengan dimediasi oleh brand love konsumen. Hal ini menunjukkan bahwa semakin tinggi brand image produk maka semakin tinggi barnd love konsumen yang selanjutnya akan meningkatkan willingness to pay price premium konsumen.

\section{Saran}

Untuk mempertahankan dan meningkatkan brand experience, brand image, brand love pada pemilik Honda HRV di Samarinda sebaiknya dealer Honda terus membangun komunikasi dengan konsumen. Komunkasi bisa dibangun dengan menggunakan berbagai aplikasi media sosial dimana hubungan antara dealer dan konsumen bisa terjalin secara intensif.

Aplikasi media sosial bisa menjadi tempat menggali informasi dari konsumen dan sekaligus bisa menjadi tempat menyampaikan keluhan konsumen terhadap produk dan pelayanan.

\section{DAFTAR PUSTAKA}

Aaker, D. A. (1991). Managing Brand Equity (1st ed.). The Free Press.

Alice M. Tybot, T. C. (2005). Kellog on Branding (1st ed.). John Wiley and Sons, Inc. Hoboken.

Anholt, S. (2010). Places: Identity, image and reputation. Houndsmills, United Kingdom: Palgrave Macmillan

Anselmsson, J., Bondesson, N. V., \& Johansson, U. (2014). Brand image and customers' willingness to pay a price premium for food brands. Journal of Product and Brand Management, 23(2), 90-102. https://doi.org/10.1108/JPBM-10-2013-0414

Bambang, Lubis, A. R., \& Darsono, N. (2017). Pengaruh Brand Image, Brand Personality,

Brand Experience Terhadap Brand Love Dampaknya Pada Brand Loyalty Gayo Aceh Coffee PT. Oro Kopi Gayo Kabupaten Aceh Tengah. Jurnal Perspektif Manajemen Dan Perbankan, 8(3), 158-184.

Batey, M. (2008). Brand Meaning (1st ed.). Routledge, New York.

Bondesson, N. (2012). Brand Image Antecedents of Loyalty and Price Premium in Business Markets. Business and Management Research, 1(1), 32-47. https://doi.org/10.5430/bmr.v1n1p32

Brakus, J. J., Schmitt, B. H., \& Zarantonello, L. (2009). Brand Experience: What Is It? How Is It Measured? Does It Affect Loyalty? 
Journal of Marketing, 73(3), 52-68. https://doi.org/10.1509/jmkg.73.3.52

Cahyani, K. I., Manajemen, J., Ekonomi, F., Semarang, U. N., \& Artikel, I. (2016). Pengaruh Brand Awareness dan Brand Image terhadap Keputusan Pembelian. Management Analysis Journal, 5(4), 281288.

Carroll, B. A., \& Ahuvia, A. C. (2006). Some antecedents and outcomes of brand love. Marketing Letters, 17(2), 79-89. https://doi.org/10.1007/s11002-006-4219-2

Chairy, T. P. D. (2019). Pengaruh Brand Loyalty, Brand Love, Brand Commitment Terhadap Willingness To Pay A Premium Price. Jurnal Manajemen Bisnis Dan Kewirausahaan, 2(1), 89-97. https://doi.org/10.24912/jmbk.v2i1.4813

Dwivedi, A., Nayeem, T., \& Murshed, F. (2018). Brand experience and consumers' willingness-to-pay (WTP) a price premium: Mediating role of brand credibility and perceived uniqueness. Journal of Retailing and Consumer Services, 44(June), 100-107. https://doi.org/10.1016/j.jretconser.2018.06. 009 Gregg, D. G., \& Walczak, S. (2010). The relationship between website quality, trust and price premiums at online auctions.

Electronic Commerce Research, 10(1), 1-25. https://doi.org/10.1007/s10660-010-9044-2

Halim, P., Swasto, B., Hamid, D., \& Firdaus, M. R. (2014). The Influence of Product Quality , Brand Image , and Quality of Service to Customer Trust and Implication on Customer Loyalty ( Survey on Customer Brand Sharp Electronics Product at the South Kalimantan Province ). Europen Journal of Business and Management, 6(29), 159-166.

Hermawan Kartajaya, Yushohardy, Jacky Mussry, T. (2005). Positioning, Diferensiasi, dan Brand (C. Rahadiansyah (Ed.); 1st ed.). PT. Gramedia Pustaka Utama.

Lee, J., James, J., \& Kim, Y. (2014). A reconceptualization of brand image. International Journal of Business Administration, 5(4), 1-11

Lee, H. M., Lee, C. C., \& Wu, C. C. (2011). Brand image strategy affects brand equity after M\&A. European Journal of Marketing, 45(7/8), 1091-1111 Bandung: Alfabeta 